\title{
TRATAMENTO DO TOPÁZIO IMPERIAL POR PREENCHIMENTO DE FRATURAS
}

\author{
GILBERTO JOSÉ ABREU MACHADO ${ }^{1}$, PAULO CÉSAR SOUZA², ANTÔNIO CLARET \\ SOARES SABIONI ${ }^{3} \&$ CÉSAR MENDONÇA FERREIRA ${ }^{2}$
}

\begin{abstract}
Resumo O tratamento do topázio imperial pelo método de preenchimento de fraturas é inédito e tem por objetivo eliminar visualmente as inclusões do tipo fraturas que atingem a superfície do mineral. Neste trabalho foi feito um estudo do aproveitamento de topázios de baixa qualidade gemológica pelo tratamento de impregnação com os fluidos Opticom 224 e $\alpha$-monobromonaftalina. $O$ princípio do método é baseado no preenchimento destas inclusões, para substituir o ar que, normalmente, preenche tais cavidades por uma substância transparente, incolor ou colorida, com índice de refração próximo ao da gema. As amostras foram selecionadas, submetidas a vácuo, seguido de imersão em Opticom 224 ou $\alpha$-monobromonaftalina ainda sob vácuo, mantidas em repouso para que a pressão atmosférica forçasse o fluido para dentro das fraturas e finalizou-se o processo com a limpeza das mesmas. $O$ incremento da massa das amostras utilizadas demonstrou que houve a percolação de fluido nas fraturas. Os resultados mostram a redução de reflexos brancos e eliminação visual de fraturas em todas as amostras após a impregnação, com melhoria da cor, transparência e brilho, mostrando que o método é adequado para aproveitamento de rejeitos de topázio imperial.
\end{abstract}

Palavras-chave: preenchimento de fraturas, topázio imperial, gemas.

\begin{abstract}
THE ENHANCEMENT OF THE IMPERIAL TOPAZ BY THE METHOD OF FILLING IN FRACTURE is unprecedented and aims to eliminate, visually, the inclusions like fractures. In this task, research about the use of the low gemological quality by a improvement of impregnation with fluids opticom 224 and $\alpha$-monobromonaftalina was completed. The method's principle is based on the filling in of its inclusions, in order to replace the air, that normally fills the cavities, with a transparent substance, color or colorless, with a refraction index close to the gema's index one. The samples were selected, submitted to vacuum, followed by immersion in opticom 224 or $\alpha$-monobromonaftalina, still in vacuum. The samples were kept dormant in order to make the atmosphere pressure force the fluid into the fractures, which are finally cleaned. The increment of the samples used demonstrated that there was percolation of the fluids in the fractures. Our results show the reduction of the white reflexions and the visual elimination of the fractures in all samples after the impregnation, with color, transparency and shining improvements, which mean that the method is suitable to use the imperial topaz rejects.
\end{abstract}

Keywords: fracture filling, imperial topaz, gems.

INTRODUÇÃO O topázio imperial é uma gema de alto valor comercial devido, principalmente, à sua raridade, beleza, e grande durabilidade como conseqüência de sua dureza. São poucas as ocorrências no mundo, sendo as principais as do Brasil, Paquistão, Sibéria e Montes Urais, porém, somente as jazidas do Brasil abastecem, de forma significativa, o mercado mundial, pois, as demais estão quase exauridas. No Brasil, é encontrado somente na região de Ouro Preto, Minas Gerais. Esta região tem sido, há mais de dois séculos, a maior produtora desta valiosa gema. O topázio é um nesossilicato de alumínio, com fórmula química $\mathrm{Al}_{2} \mathrm{SiO}_{4}\left[(\mathrm{OH})_{1-\mathrm{x}} \mathrm{F}_{\mathrm{x}}\right]_{2}$, onde a hidroxila pode substituir o flúor em até aproximadamente $30 \mathrm{~mol} \%$ (Barton 1982). Para o topázio imperial, o valor de " $\mathrm{x}$ " é de 0,80 (Costa et al. 2000).

A gênese do topázio imperial está relacionada a processos hidrotermais (Keller 1983, Ferreira 1991). Para Keller (1983) os veios quartzo-fedspáticos com topázio foram formados por fluidos ricos em flúor que invadiram o Supergrupo Minas, preenchendo fendas formadas quando as rochas foram arqueadas por intrusões graníticas. Com o intemperismo químico profundo de grande parte das rochas da região, os veios também acabaram sendo intemperizados. Ferreira (1983) sugeriu que as falhas, provavelmente, reativadas durante um evento tectônico no final do Cretáceo ou início do Terciário, deram origem a focos de vulcanismo que produziram soluções hidrotermais saturadas em sílica responsáveis pela formação do topázio. Ferreira (1991) acredita que a mineralização de topázio na região de Ouro Preto esteja relacionada a dolomitos do Grupo Piracicaba, mas tam- bém afirma que o controle estrutural e a atividade hidrotermal foram os principais fatores na formação do topázio.

As ocorrências primárias de topázio imperial da região de Ouro Preto estão relacionadas às rochas carbonáticas do Supergrupo Minas, que apresentam metamorfizadas e fortemente alteradas, sendo raros os afloramentos em rochas sãs (Gandini 1994). O único local descrito onde o topázio é encontrado em rocha inalterada está a 500m da Rodovia dos Inconfidentes, $\mathrm{km} 14$ num local denominado Bocaina, sendo constituído por um mármore dolomítico pertencente à Formação Fecho do Funil, Grupo Piracicaba, Supergrupo Minas (Ferreira 1991, Gandini 1994).

A maioria dos cristais de topázio imperial apresenta inclusões do tipo fraturas, visíveis a "olho nu", preenchidas por gás, e orientadas com tendência paralela ao eixo " $c$ " cristalográfico, $\mathrm{e}$, devido a isso, apenas cinco porcento é de qualidade gemológica. Este mineral-gema é, tradicionalmente, lapidado e comercializado isento de inclusões para alcançar liquidez e maior valor de mercado, reduzindo, de forma significativa, o seu aproveitamento na lapidação que, raramente, ultrapassa cinco por cento do cristal primário, ou seja, "seu estado bruto" . A possibilidade de lapidar topázios com algumas inclusões, resulta em maior aproveitamento do "bruto" e maior intensidade de cor, devido ao aumento do caminho ótico percorrido pela luz dentro da gema, incrementando, desta forma, seu valor comercial. Por outro lado, a presença de inclusões do tipo fraturas, desvaloriza e reduz a liquidez da gema uma vez que geram reflexos brancos e coloridos que bloqueiam a passagem de luz pela gema, reduzindo a transparência e o brilho,

\footnotetext{
1 - Departamento de Geologia/Escola de Minas/Universidade Federal de Ouro Preto - DEGEO/EM/UFOP - Pça Cláudio Manoel, 58 - Centro. CEP 35.420-000 Mariana (MG) - machado@cefetop.edu.br

2 - Departamento de Geologia/Escola de Minas/Universidade Federal de Ouro Preto - DEGEO/EM/UFOP - CEP 35.400-000 Ouro Preto (MG) - souzacfs@ouropreto. feop.com.br

3 - Departamento de Física. Universidade Federal de Ouro Preto. 35400 000, Ouro Preto, Brasil.
} 
além de deixarem as gemas com cores mais pálidas. Ao introduzir fluidos nestas fraturas, pode-se observar a eliminação dos reflexos brancos e coloridos resultando em uma inclusão opticamente menos visível a "olho nu".

O processo de preenchimento de fraturas já é utilizado, em gemas, desde a época da Grécia e Roma antiga, porém, é aceito e difundido internacionalmente para esmeralda, coríndon e diamante, sendo inédita a sua aplicação em topázio. As fraturas, fissuras ou fendas originadas de tensão mecânica, pressão e/ou temperatura acentuadas, contém originalmente vácuo, gás ou fluido(s) e se tais fraturas ou cavidades alcançam a superfície da pedra, elas geralmente estão preenchidas por ar (Hãnni $1992 \mathrm{a}, \mathrm{b})$. O princípio do método é baseado no preenchimento de fraturas e/ou cavidades, para substituir o ar que normalmente preenche tais cavidades por uma substância transparente, essencialmente incolor, que tenha um índice de refração muito próximo ao da gema e desse modo resultar em uma inclusão menos visível (Hãnni 1992a, Koivula \& Kammerling 1988), que poderá aumentar o aproveitamento de topázio imperial. Diversos autores realizaram estudos sobre impregnação de esmeraldas, coríndon e diamantes, entre eles Lindberg 1972, Ringsrud 1983, Roeder 1984, Hughes 1984, 1987, Scarratt et al. 1986, Koivula 1987a,b, Koivula e Kammerling 1988, Matlins 1989 , Kammerling et al. 1991, Nassau 1991, 1994a,b, Sechos 1994, Hänni 1992a,b, Moses 1994, Levy 1994,1996,1997, Johnson et al. 1999 e Polli 1999.

Diversas substâncias orgânicas no estado líquido, em condições físico-químicas apropriadas, tornam-se sólidas através de polimerização após adição de um catalisador (endurecedor ou agente de cura). As duas partes podem ser misturadas em quantidades iguais ou diferentes, dependendo do tipo de resina (Kammerling et al. 1991, Hãnni 1992a,b). Um exemplo de polímero é o Opticon 224, freqüentemente utilizado na impregnação de esmeraldas.

A permanência e a estabilidade dos impregnantes são variáveis e dependem de suas características físico-químicas. Alguns tipos de resinas e óleos podem ressecar tornando-se opacos, pois reagem com o oxigênio atmosférico. Se a pedra é aquecida eles podem queimar ou vazar. Sol forte, solventes, bebidas alcoólicas ou limpeza em ultra-som podem removê-los parcialmente.

Independente da composição química da substância usada, este tratamento altera a aparência natural da gema preciosa. Conseqüentemente, a ética profissional exige que este tratamento seja revelado e divulgado ao consumidor.

\section{MATERIAIS E MÉTODOS}

Preparação das amostras As amostras estudadas foram doadas pelas empresas de mineração Capão do Lana e Vermelhão ao Centro de Tecnologia de Gemas do Departamento de Geologia da Escola de Minas da Universidade Federal de Ouro Preto (CTG/DEGEO/EM/UFOP). Foram selecionadas 36 amostras de um lote de 1360 gramas em função da cor, tamanho e diafaneidade. As cores consideradas foram amarela, laranja, laranja-acastanhada, rosa-clara, a rosa-escura, lilás, vermelha e vermelho-acastanhada. Quanto à diafaneidade, somente amostras transparentes foram aproveitadas. Quanto ao tamanho, somente as amostras superiores a 5 milimetros foram consideradas por apresentar melhor nitidez nas fotografias.

LIMPEZA As operações de limpeza das fraturas e/ou cavidades superficiais das amostras, foram realizadas no Laboratório de Geoquímica do DEGEO/EM/UFOP e de Química da CEFET OP.

Detergentes ou solventes (hidróxido de sódio, álcool, acetona) e ácidos (clorídrico, nítrico, água régia), a quente e a frio, foram utilizados para limpar as amostras de topázio. Essas subs- tâncias foram escolhidas, levando-se em consideração procedimentos estabelecidos por Polli (1999), desenvolvidos para limpeza de esmeraldas.

Inicialmente as amostras foram lavadas com detergente em um recipiente plástico com água morna. Para remover sujeiras ou manchas também foram utilizados, ácidos fracos ou diluídos, ácidos fortes, particularmente ácido hidroclorídrico (muriático) e ultra-som. Foi empregada solução de ácido oxálico para lixiviação de manchas de óxidos hidratados de ferro e solventes orgânicos (acetona, álcool metílico, álcool etílico e um pouco de amônia) para remover todos os indícios de gordura, graxa ou óleo. Também foram utilizadas escova de dentes de cerdas rígidas, buril de ourives, vareta de madeira com ponta fina e ultrasom para remover porções resistentes de sujeira. Limpadores ultra-sônicos usam ondas de freqüência muito alta que formam pequenas bolhas que implodem junto à gema ao ser limpa, causando pequenos vácuos que puxam a sujeira para fora da mesma (Polli 1999). Foi utilizada uma lupa com aumento de 10X para examinar o material antes, durante e depois da limpeza. A operação final de limpeza das gemas foi concluída com água limpa e morna. Depois as amostras foram secadas naturalmente ao ar ou empregando ar quente de um secador de cabelo.

LAPIDAÇÃO DAS AMOSTRAS No laboratório de lapidação da CEFET OP as amostras foram serradas, formadas, facetadas e polidas, levando-se em consideração seu melhor aproveitamento tanto em cor quanto em tamanho.

DOCUMENTAÇÃO DAS AMOSTRAS As amostras foram documentadas através de uma máquina fotográfica digital marca Sony DSC 85 de 3,4 mega pixels, com controle de branco, montada em tripé a uma distância fixa das mesmas. As amostras foram dispostas em fundo padronizado, em ambiente escuro e iluminadas diretamente por lâmpada fria.

PESAGEM DAS AMOSTRAS Todas as amostras tratadas foram pesadas com balança marca Sartorius de alta precisão $(0,00001 \mathrm{~g})$. A tabela 01 mostra a medida das massas das amostras antes do tratamento, após a limpeza, depois do tratamento e a variação percentual em massa e volume.

Impregnação das amostras Para este trabalho dois fluidos foram escolhidos em função de seu valor e sua disponibilidade no mercado, bem como por apresentarem índices de refração próximos ao do topázio imperial, ou seja 1,610 a 1,630. Um deles foi o $\alpha$-monobromonaftalina e o outro o Opticon 224. $\mathrm{O} \alpha$ monobromonaftalina tem índice de refração próximo de 1,656 , é tóxico, incolor e volátil. Já o Opticon 224 apresenta índice de refração próximo de 1,570 , é tóxico, incolor, viscoso. Para a impregnação do topázio com esses fluidos, foi desenvolvido um sistema interligado a uma bomba de vácuo com um recipiente para as amostra e outro para os fluidos, sendo realizada em amostras lapidadas que foram colocadas em uma câmara de vácuo a uma pressão constante de $(-700 \mathrm{mmHg})$. Foi feito aplicaç̃̃es de vácuo eliminando o ar da câmara, bem como das fraturas das gemas por um período de dez minutos. Em seguida, adicionou-se, lentamente, fluido impregnante até cobrir toda gema, mantendo-se a bomba de vácuo ligada, até observar o desaparecimento das bolhas de ar, que saiam das fraturas. Abriu-se o registro que permitia a entrada de ar no sistema para o re-estabelecimento da pressão atmosférica, e manteve as amostras imersas em impregnantes por 24 horas para que o fluido fosse forçado a percolar as fraturas, até que as pressões internas e externas se igualassem. As amostras foram retiradas do sistema, efetuou sua limpeza, mediu sua massa e fez seu re-gistro fotográfico. 


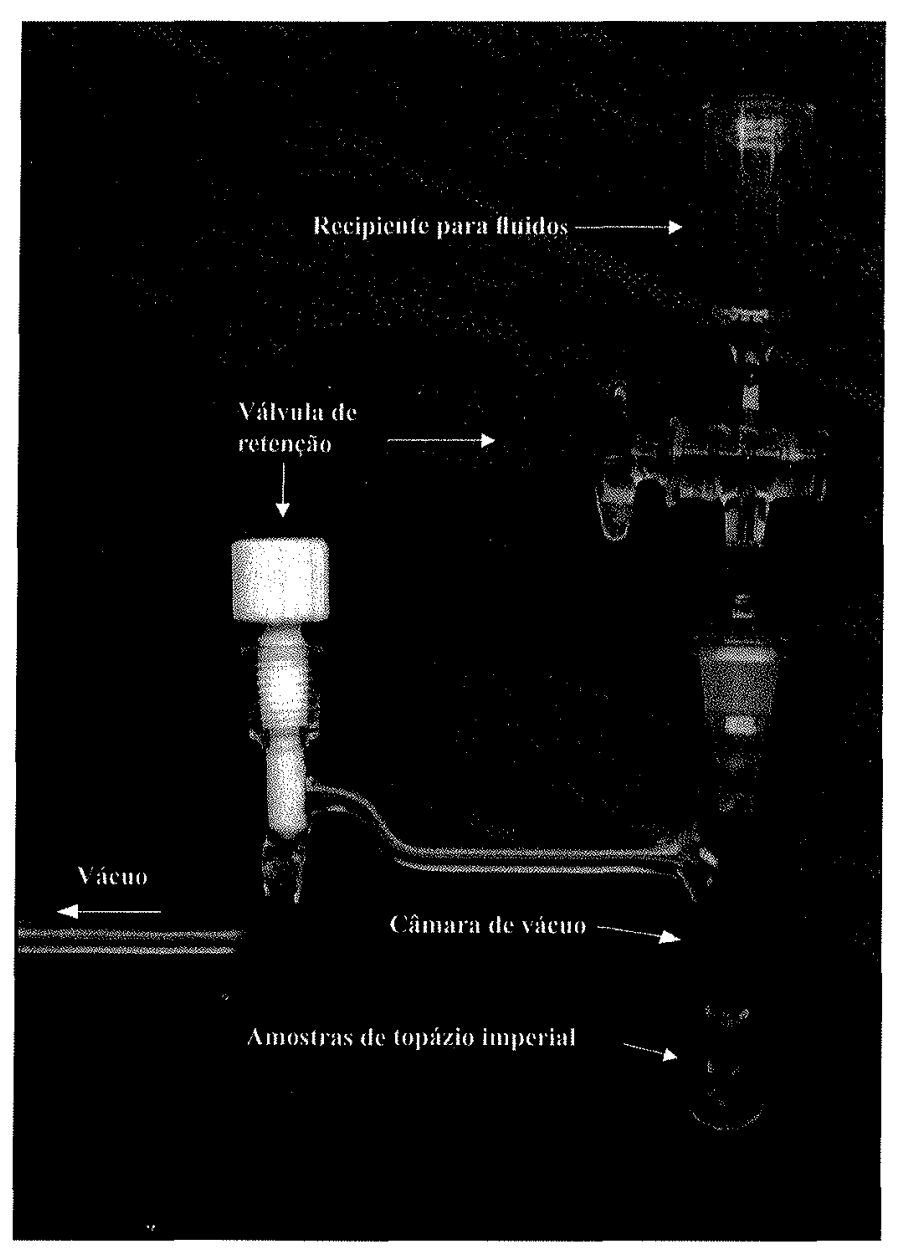

Figura 01- Sistema de impregnação desenvolvido para o preenchimento de fraturas do topázio imperial

IMPREGNAÇÃO COM OPTICON 224 INCOLOR As amostras foram colocadas em cadinhos de porcelana e introduzidas no interior de um secador de areia onde foram aquecidas através de uma lâmpada de $150 \mathrm{~W}$, para aumentar a fluidez das substâncias. Ao mesmo tempo o Opticon foi colocado em um tubo de ensaio e levado a um béquer contendo água fervente e mantido aquecido até o momento de sua utilização. As amostras aquecidas foram colocadas na câmara de vácuo do sistema de impregnação (Figura 01) e submetidas a vácuo, durante cerca de dez minutos cada uma. A aplicação de vácuo, combinado com aquecimento da resina entre $60^{\circ} \mathrm{C}$ e $80^{\circ} \mathrm{C}$ facilitou a sua penetração nas fraturas das gemas. O Opticon 224 aquecido foi introduzido ao sistema até a imersão total das amostras que também estavam aquecidas, manteve-se o vácuo, após a imersão, por um período de uma hora, durante o qual foi observado o aparecimento de uma grande quantidade de bolhas (o aspecto é como se a resina estivesse efervescente). Após um repouso de dez minutos, foi aplicado vácuo novamente por mais uma hora. Foi observado que, a quantidade de bolhas ia desaparecendo gradativamente de uma aplicação para a outra, diminuindo bastante na segunda e desaparecendo na terceira. Desligou-se o sistema de vácuo e manteve as amostras imersas em Opticom por vinte e quatro horas.

As amostras foram retiradas da câmara de vácuo, deixandose que o Opticon 224 escorresse para o seu reaproveitamento e em seguida foram colocadas e movimentadas sobre pano macio, limpo e seco, substituindo-o por outro quando necessário até eliminar o excesso de Opticon 224. Posteriormente, foi efetuada a limpeza final das amostras com papel absorvente.
Para verificar a qualidade ou eficiência da impregnação, as amostras foram pesadas e analisadas através de lupa binocular, e, quando esta não foi considerada satisfatória, as amostras foram novamente submetidas a impregnação.

As fraturas foram seladas com uma mistura da própria resina e catalisador, para evitar que a mesma saísse com o tempo.

A utilização do endurecedor nas amostras já impregnadas com Opticon 224, foi feita de duas maneiras:

a) gotejando endurecedor diretamente sobre as amostras e limpando-as dez minutos mais tarde.

b) preparando uma mistura composta de dez partes da resina e uma parte de endurecedor e aplicando-a sobre a superfície das amostras ou cobrindo-as com certa camada desta mistura. Em seguida as amostras foram mantidas imersas em repouso, à temperatura ambiente e durante dez minutos.

Posteriormente, sem perder muito tempo, ou seja, antes da mistura endurecer, foi providenciada a limpeza superficial das amostras utilizando pano e papel absorvente. A limpeza final tem que ser muito bem feita e antes da mistura ou resina endurecer, porque não existe solvente eficiente para remover ou eliminar Opticon 224 endurecido, mesmo que sob forma de resíduos. Se isto acontecer a remoção deverá ser feita via repolimento.

\section{IMPREGNAÇÃO COM $\alpha$-MONOBROMONAFTALINA}

As amostras foram aquecidas e levadas à câmara de vácuo Fez-se duas aplicações de vácuo por dez minutos intercalado por um período de dois minutos de repouso. O fluido foi derramado sobre as amostras mantendo-se o sistema sob vácuo por uma hora, quando observou a geração de muitas bolhas que davam a aparência de estarem fervendo. A partir daí, mantevese o sistema de vácuo em funcionamento até o desaparecimento total das bolhas. Desligou-se a bomba de vácuo e deixou que a pressão atmosférica se re-estabelecesse. Lacrou-se o sistema para evitar a evaporação do fluido e manteve as amostra imersas, por vinte e quatro horas, para que as pressões internas e externas se igualassem.

As amostras foram retiradas da câmara de vácuo e procedeu-se à limpeza final com papel absorvente.

RESULTADOS E DISCUSSÕES Os topázios foram lapidados com inclusões, o que resultou em maior quilatagem e maior intensidade de cor, devido às maiores dimensões dos mesmos. Isto é explicado pelo maior caminho ótico percorrido pela luz no interior da gema que intensifica a cor.

Por outro lado, a presença de inclusões do tipo fraturas desvalorizou as gemas uma vez que geraram reflexos brancos e coloridos que realçaram as fraturas e bloquearam a passagem de luz pela gema, reduzindo sua transparência e seu brilho, além de deixar as gemas com aspecto fosco e mais pálidas, devido à mistura dos reflexos brancos com a reflexão dos espectros de luz que definem a cor dos topázios.

O sistema de impregnação utilizado permitiu a injeção do impregnante para dentro das fraturas que interceptavam a superfície externa dos topázios. Isto pode ser constatado através da utilização da microscopia ótica, onde pode ser observado feições típicas de "fraturas preenchidas por fluidos".

Os resultados obtidos após a impregnação dos fluidos já descritos, foram similares. As fraturas tornaram-se menos visíveis a "olho nu" e pode-se notar o aumento da transparência e a intensificação da cor e do brilho dos topázios.

As figuras 02 e 03 mostram topázios impregnados com $O p$ ticon 224 e $\alpha$-monobromonaftalina, respectivamente.

$\mathrm{O} \alpha$-monobromonaftalina que preenchia as fraturas dos topázios mostrados na figura 03, por ser volátil, após dois dias da sua utilização, evaporou-se deixando um resíduo sólido amarelado nos topázios. Já o Opticon 224 (figura 02), permane- 

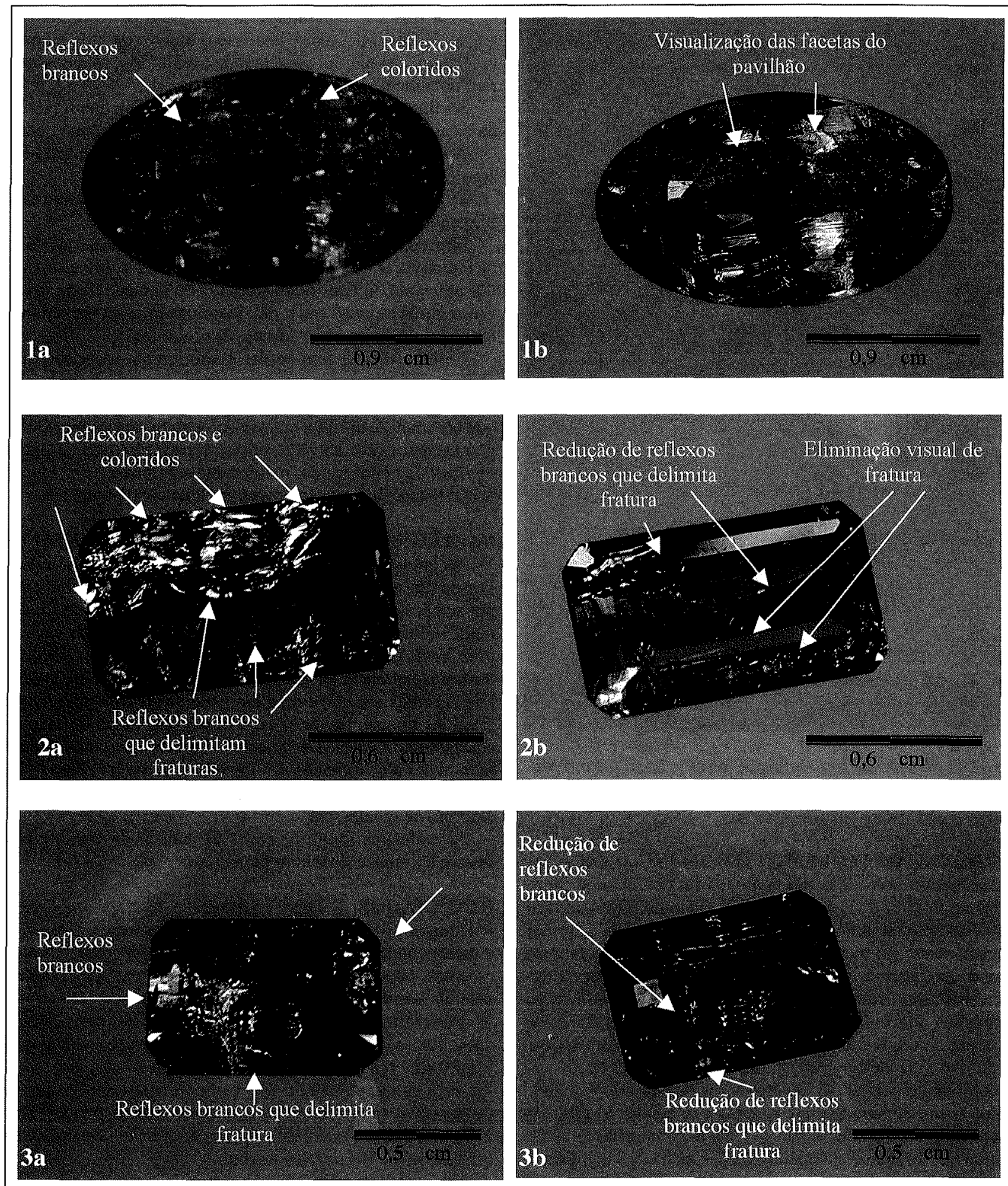

Figura 2 - Fotografias de amostras de topázio imperial antes da impregnação (coluna da esquerda) e após a impregnação com a-monobromonaftalina (coluna da direita). Fotos de Antônio Liccardo 2002.

ceu inalterado por mais de noventa dias. Os líquidos utilizados apresentaram bons resultados, melhorando as propriedades óticas dos topázios tratados.

Os registros fotográficos mostram a redução dos reflexos brancos e coloridos, bem como o desaparecimento visual das inclusões do tipo fraturas após impregnação. Isto pode ser constatado pela melhor visualização e nitidez da geometria das facetas do pavilhão.
Alguns reflexos brancos permaneceram nas gemas tratadas. Isto provavelmente aconteceu devido, principalmente, à ausência de comunicação entre a fratura e a parte externa da gema.

De acordo com os dados das medidas das massas das amostras antes e depois da impregnação (Tabela 01), observa-se que houve incremento de massa em todas as amostras impregnadas, porém, sem alterar o valor quanto ao desprezível ganho de massa, uma vez que o valor de gemas lapidadas somente leva em 
consideração a segunda casa decimal.

O valor do topázio imperial está relacionado, principalmente, com sua cor e inclusões. Quanto à cor, os mais valiosos são os que apresentam maior intensidade para as colorações avermelhadas e rosadas. As cores mais pálidas são menos valorizadas, pois apresentam pouco contraste com os metais utilizados em joalherias. As cores verdes, amarelas esverdeadas, azuis e incolores são raras, porém de pouco valor comercial, mesmo assim, são procuradas por pesquisadores e colecionadores.

A presença de inclusões do tipo fratura visíveis a "olho nu", além de reduzir o valor econômico desta gema, exerce grande influência negativa em sua liquidez. Este valor por unidade de massa aumenta consideravelmente para topázios entre 2 e 15 quilates, pois são os mais procurados pela indústria joa-lhei-
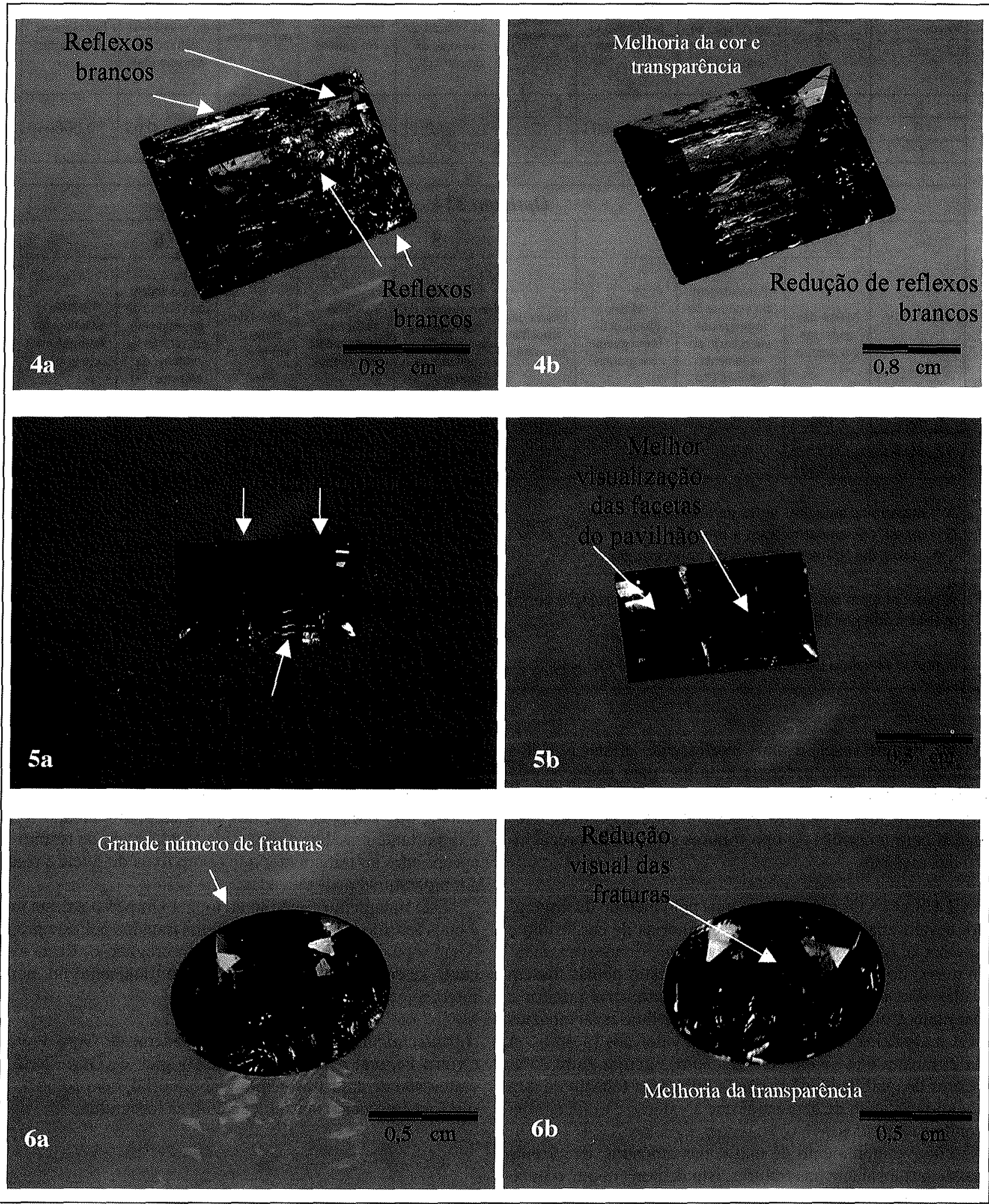

Figura 3 - Fotografias de amostras de topázio imperial antes da impregnação (coluna esquerda) e depois da impregnação com Opticon 224 (coluna direita). Fotos de Antônio Liccardo 2002 
Tabela 01 - Massa das amostras antes da limpeza, após a limpeza, depois do tratamento, a massa do impregnante e a porcentagem em volume do impregnante em relação ao volume da amostra.

\begin{tabular}{|c|c|c|c|c|c|c|c|c|c|}
\hline \multicolumn{10}{|c|}{$\alpha$-Monobromonaftalina } \\
\hline & \multicolumn{3}{|c|}{1} & \multicolumn{3}{|c|}{2} & \multicolumn{3}{|c|}{3} \\
\hline Amostras & $\begin{array}{c}\text { Massa das } \\
\text { amostras } \\
\text { em gramas }\end{array}$ & $\begin{array}{l}\text { Porcentagem } \\
\text { em volume do } \\
\text { impregnante } \\
\text { em relação ao } \\
\text { volume da } \\
\text { amostra }(\%)\end{array}$ & $\begin{array}{c}\text { Massa } \\
\text { absoluta do } \\
\text { Impregnante } \\
\text { em gramas }\end{array}$ & $\begin{array}{c}\text { Massa das } \\
\text { amostras } \\
\text { em gramas }\end{array}$ & $\begin{array}{l}\text { Porcentagem } \\
\text { em volume do } \\
\text { impregnante } \\
\text { em relação ao } \\
\text { volume da } \\
\text { amostra }(\%)\end{array}$ & $\begin{array}{c}\text { Massa } \\
\text { absoluta do } \\
\text { Impregnante } \\
\text { em gramas }\end{array}$ & $\begin{array}{c}\text { Massa das } \\
\text { amostras } \\
\text { em gramas }\end{array}$ & $\begin{array}{c}\text { Porcentagem } \\
\text { em volume do } \\
\text { impregnante } \\
\text { em relação ao } \\
\text { volume da } \\
\text { amostra (\%) }\end{array}$ & $\begin{array}{c}\text { Massa } \\
\text { absoluta do } \\
\text { Impregnante } \\
\text { em gramas }\end{array}$ \\
\hline $\mathrm{A}$ & 2,44228 & \multirow{3}{*}{0,04} & \multirow{3}{*}{0,00033} & 0,82179 & \multirow{3}{*}{0,11} & \multirow{3}{*}{0,00029} & 0,57363 & \multirow{3}{*}{0,03} & \multirow{3}{*}{0,000050} \\
\hline $\mathrm{B}$ & 2,44205 & & & 0,82163 & & & 0,57295 & & \\
\hline $\mathrm{C}$ & 2,44238 & & & 0,82192 & & & 0,57300 & & \\
\hline \multicolumn{10}{|c|}{ Opticom 224} \\
\hline & \multicolumn{3}{|c|}{4} & \multicolumn{3}{|c|}{5} & \multicolumn{3}{|c|}{6} \\
\hline Amostras & $\begin{array}{c}\text { Massa das } \\
\text { amostras } \\
\text { em gramas }\end{array}$ & $\begin{array}{c}\text { Porcentagem } \\
\text { em volume do } \\
\text { impregnante } \\
\text { em relação ao } \\
\text { volume da } \\
\text { amostra (\%) }\end{array}$ & $\begin{array}{c}\text { Massa } \\
\text { absoluta do } \\
\text { Impregnante } \\
\text { em gramas }\end{array}$ & $\begin{array}{c}\text { Massa das } \\
\text { amostras } \\
\text { em gramas }\end{array}$ & $\begin{array}{l}\text { Porcentagem } \\
\text { em volume do } \\
\text { impregnante } \\
\text { em relação ao } \\
\text { volume da } \\
\text { amostra (\%) }\end{array}$ & $\begin{array}{c}\text { Massa } \\
\text { absoluta do } \\
\text { Impregnante } \\
\text { em gramas }\end{array}$ & $\begin{array}{c}\text { Massa das } \\
\text { amostras } \\
\text { em gramas }\end{array}$ & $\begin{array}{c}\text { Porcentagem } \\
\text { em volume do } \\
\text { impregnante } \\
\text { em relação ao } \\
\text { volume da } \\
\text { amostra (\%) }\end{array}$ & $\begin{array}{c}\text { Massa } \\
\text { absoluta do } \\
\text { Impregnante } \\
\text { em gramas }\end{array}$ \\
\hline $\mathrm{A}$ & 2,10455 & \multirow{3}{*}{0,04} & \multirow{3}{*}{0,00039} & 0,46699 & \multirow{3}{*}{0,15} & \multirow{3}{*}{0,00029} & 0,46057 & \multirow{3}{*}{0,09} & \multirow{3}{*}{0,00018} \\
\hline $\mathrm{B}$ & 2,10422 & & & 0,46678 & & & 0,46045 & & \\
\hline $\mathrm{C}$ & 2,10461 & & & 0,46707 & & & 0,46063 & & \\
\hline \multicolumn{10}{|c|}{$\begin{array}{l}\mathrm{A}=\text { massa das amostras antes da limpeza } \\
\mathrm{B}=\text { massa das amostras após a limpeza } \\
\mathrm{C}=\text { massa das amostras depois da impregnação } \\
\text { A porcentagem em volume do impregnante em relação ao vol } \\
\text { multiplicado por } 100 \\
\text { A massa absoluta do impregnante representa a variação de ma }\end{array}$} \\
\hline
\end{tabular}

ra. Assim, muitas vezes, é mais interessante lapidar topázios com algumas inclusões e depois tratá-los, para alcançar esta faixa de peso. A tabela 02 mostra o percentual da valorização dos topázios lapidados sem inclusões comparados com aqueles lapidados com inclusões do tipo fraturas seguido de preenchimento das mesmas.

CONCLUSÃO Os topázios tratados pelo método de impregnação, neste trabalho, apresentaram melhorias de cor, brilho e transparência. Isto proporcionou obter um maior aproveitamento em massa do cristal primário, pois caso estas gemas fossem lapidadas sem inclusões, este aproveitamento seria inferior a meio quilate. Como conseqüência destas melhorias os topázios ficaram mais belos, de forma a agregar valor aos mesmos. A tabela 2 mostra que houve valorização das gemas entre $25 \%$, para cores de qualidade inferior e de $66 \%$ para topázio de melhor qualidade, além de demostrar que a valorização foi similar para ambos os fluidos.

Não houve incremento de massa nas amostras, decorrente da massa da substância nas fraturas, isto demonstra que o tratamento não é lesivo ao cliente.

Os impregnantes utilizados neste trabalho são instáveis, danificando-se com o tempo, e devem ser devidamente acondicionados para não vazar ou escurecer. Estas informações devem ser prestadas ao cliente, para que ele tome as devidas precauções.

O tratamento do topázio por impregnação é viável, uma vez que deixa as gemas mais belas, inclusive as consideradas cascalhos, que sempre foram desprezadas pelo mercado. Porém, é importante ressaltar a necessidade do estudo de resinas mais apropriadas ao tratamento, que sejam mais duráveis e resistam a temperaturas mais elevadas.

Este tratamento é inédito ao topázio imperial e desta forma, é mais sensato classificar os topázios tratados por este processo como topázio imperial tratado por impregnação. Resta avaliar como se comportará a aceitação deste tratamento no mercado internacional.

Agradecimentos à Universidade Federal de Ouro Preto e à Centro Federal de Educação Tecnológica de Ouro Preto pela concessão de amostras e apoio laboratorial, bem como a Antônio Liccardo pela contribuição com as fotografias. 
Tabela 02 - Aumento percentual do valor das amostras lapidadas com inclusões seguidas de impregnação

\begin{tabular}{|c|c|c|c|c|c|c|c|c|c|c|c|c|}
\hline \multicolumn{13}{|c|}{$\alpha$-Monobromonaftalina } \\
\hline \multirow[b]{2}{*}{ Amostras } & \multicolumn{4}{|c|}{1} & \multicolumn{4}{|c|}{2} & \multicolumn{4}{|c|}{3} \\
\hline & ct & US\$/ct & US\$/pedra & 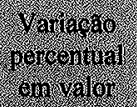 & ct & US\$/ct & US\$/pedra & 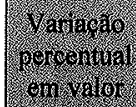 & ct & US $\$ / \mathrm{ct}$ & US\$/pedra & 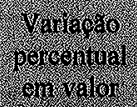 \\
\hline A & \multirow[b]{2}{*}{12,21} & 0,80 & 9,77 & \multirow{2}{*}{ 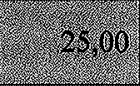 } & \multirow[b]{2}{*}{4,11} & 0,80 & 3,29 & \multirow{2}{*}{2.20} & \multirow[b]{2}{*}{2,87} & 1,80 & 5,16 & \multirow{2}{*}{ 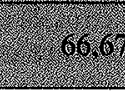 } \\
\hline $\mathrm{B}$ & & 1,00 & 12,21 & & & 1,00 & 4,11 & & & 3,00 & 8,60 & \\
\hline \multicolumn{13}{|c|}{ Opticom } \\
\hline \multirow[b]{2}{*}{ Amostras } & \multicolumn{4}{|c|}{4} & \multicolumn{4}{|c|}{5} & \multicolumn{4}{|c|}{6} \\
\hline & ct & $\mathrm{US} \$ / \mathrm{ct}$ & US\$/pedra & 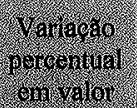 & $\mathrm{ct}$ & US $\$ / \mathrm{ct}$ & US\$/pedra & \multirow{3}{*}{ 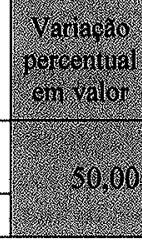 } & ct & US $\$ / \mathrm{ct}$ & US\$/pedra & \multirow{3}{*}{ 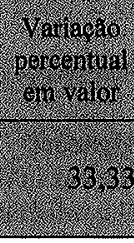 } \\
\hline A & \multirow[b]{2}{*}{10,52} & 2,00 & 21,05 & 5060 & \multirow[b]{2}{*}{2,33} & 2,00 & 4,67 & & \multirow[b]{2}{*}{2,30} & 1,50 & 3,45 & \\
\hline $\mathrm{B}$ & & 3,00 & 31,57 & rex & & 3,00 & 7,00 & & & 2,00 & 4,61 & \\
\hline \multicolumn{9}{|c|}{$\begin{array}{l}A=\text { amostras lapidadas sem inclusões } \\
B=\text { amostras lapidadas com inclusões seguidas de impregnação }\end{array}$} & \multicolumn{4}{|c|}{$\mathrm{ct}=$ quilate $=0,2$ gramas } \\
\hline
\end{tabular}

\section{Referências}

Barton M.D., Haselton H.T.Jr., Hemingway B.S., Kleppa O.J., Robie R.A. 1982. The thermodynamic properties of fluor topaz. The American Mineralogist, 67:350-355.

Costa G.M., Sabioni A.C.S., Ferreira C.M. 2000. Imperial topaz from Ouro Preto, Brasil: chemical character and thermal behaviour. The Journal of Gemmology, 27:133-138.

Ferreira C.M. 1991. Topázio de Ouro Preto, Minas Gerais. In: C. Schobbenhaus, E.T. de Queiroz, C.E.S., Coelho (eds.) Principais Depósitos Minerais do Brasil. Brasília, DNPM/CPRM, v. 4, p. 303-308.

Gandini A.L. 1994. Mineralogia, inclusões fluidas e aspectos genéticos do topázio imperial da região de Ouro Preto, Minas Gerais. Dissertação de Mestrado, Inst. de Geociências, Universidade de São Paulo, São Paulo, 212

Hänni H.A. 1992a. New fracture filling materials have replaced oil. ICA Gazette, 3:4-5.

Hänni H.A. 1992b. Identification of fissure-treated gemstones. The Journal of Gemmology, 23:201-205.

Hughes R.W. 1984. Surface Repaired Rubies. The Australian Gernmologist, 15:279-280.

Hughes R.W. 1987. The Plastic Coating of Gemstones. The Australian Gemmologist, 16:259-261.

Johnson M.L., Elen S., Muhlmeister 1999. On the Identification of Various Emerald Filling Substances. Gems \& Gemology, 35:82-107.

Kammerling R.C., Koivula J.I., Kane R.E., Maddison P., Shigley J.E., Fritsch E. 1991. Fracture filling of emeralds: opticon and traditional "oils". Gems \& Gemology, 27:70-85.

Keller P.C. 1983. The Capão topaz deposit, Ouro Preto, Minas Gerais, Brazil. Gems \& Gemology, 19:12-20.

Koivula J.I. 1987a. Gem News: "Filled" diamonds. Gems \& Gemolo gy, 23:172-172.

Koivula J.I. 1987b. Gem News: Plasticized emeralds. Gems \& Gemology, 23:175-175.

Koivula J.I. \& Kammerling R.C. 1991. Gem News: Colored Opticon for emeralds. Gems \& Gemology, 27:52-53.

Koivula J.I. \& Kammerling R.C. 1988. Gem News: "Filled" diamond update. Gems \& Gemology, 24:248-249.

Levy H. 1994. Around the trade: fissure filling of gemstone/emeralds/ Opticon filled emeralds. Gems and Jewellery News, 3:35-37.

Levy H. 1996. Declaration of treatments/ Emeralds. Gems and Jewellery News, 5:36-37.

Levy H. 1997. Coloured fillers. Gems and Jewellery News, 6:52-52.

Lindberg J.D. 1972. Changing the colors of transparent gemstones. The Lapidary Journal, 26:604-611.

Matlins A.L. 1989. Gem identification made easy: a hands-on guide to more confident buying and selling. 1 ed., GemStones Press, A Division of Long Hill Partners, Inc., New York, 270 p.

Moses T. 1994. Carved Emerald Fetish. In: R.C. Kammerling \& C.W. Fryer, 1994. Gem Trade Lab Notes. Gems \& Gemology, 30:264265.

Nassau K. 1991. Gass at a glance. The Lapidary Journal, 45:26-31.

Nassau K. 1994a. More on the antiquity of emerald oiling. The Journal of Gemmology, 24:109-110.

Nassau K. 1994b. Gemstones Enhancement-History, Science and State of the Art. 2 ed. London, Butterworths-Heinemann Ltd, $252 \mathrm{p}$.

Olsen D.R. 1971. Origin of topaz deposits near Ouro Preto, Minas Gerais, Brazil. Economic Geologv, 66:627-631.

Polli G. de O. 1999. Tratamento de inclusões em esmeraldas da mina de Belmont, Itabira (MG). Dissertação de Mestrado, Escola de Minas, Universidade Federal de Ouro Preto, Ouro Preto, $245 \mathrm{p}$.

Ringsrud R. 1983. The oil treatment of emeralds in Bogotá, Colômbia. Gems \& Gemology, 19:149-156.

Roedder E. 1984. Fluid inclusions. Mineralogical Society of America, 12:1-644

Scarratt K., Harding R.R., Din V.K. 1986. Glass fillings in sapphire. The Journal of Gemmology, 20:203-207.

Sechos B. 1994. Fracture filled diamonds. The Australian Gemmologist, 18:379-385.

Manuscrito A-1387 Revisão aceita em 18 de agosto de 2006 